\title{
Evaluation of Musculoskeletal Disorders Prevalence during Oil Palm Fresh Fruit Bunches Harvesting Using RULA
}

\author{
Mokhtar, M.M. ${ }^{a}$, Deros, B.M. ${ }^{b}$ and Sukadarin, E.H. ${ }^{\mathrm{c}}$ \\ Department of Mechanical and Materials Engineering, \\ Faculty of Engineering and Built Environment, \\ Universiti Kebangsaan Malaysia, \\ 43600 Bangi, Selangor, Malaysia

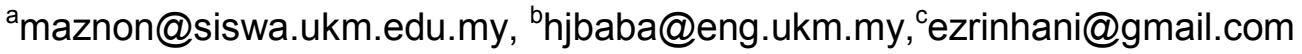

Keywords: Prevalence, WMSD, RULA, oil palm harvesters

\begin{abstract}
Prevalence of work-related musculoskeletal disorders (WMSD) in the agricultural industry is a very serious problem but it is not well investigated and understood. In this paper, the authors have made an attempt to evaluate the prevalence of WMSD in oil palm industry during harvesting fresh fruit bunches (FFB). Data collection was conducted by conducting face-to-face structured interviews with FFB harvesters. In addition, video recording on seven FFB harvesters were conducted while they are performing the harvesting work. Demographic data shows that the mean age of FFB harvester was 41.3 years and 71.4\% of them are smokers. Rapid Upper Limb Assessment (RULA) method was used to evaluate the prevalence of WMSD by observing the working postures of the FFB harvesters. RULA analysis of the observed results showed that $83 \%$ of the FFB harvesters have scored 7 during harvesting work, which means postural changes must be carried out immediately. Meanwhile, 17\% FFB harvesters have scored 5, which means postural change must be carried out soon. Repetitive work is also a main factor that contributes to high prevalence of WMSD among FFB harvesters while they are pulling and pushing the FFB.
\end{abstract}

\section{Introduction}

Palm oil cultivation is the main crop in Malaysia nowadays. Therefore, many workers are involved in this area, starting from planting until producing and selling the oil palm based products to the consumer. In terms of employment, it is estimated more than 405,000 workers are involved and accommodate more than 200000 families through the Organized Land Development Scheme [1]. On average, 50 laborers are needed for one hectare land per day to work on the oil palm plantation [2]. Among the works to be done by workers in oil palm plantations is harvesting FFB before being sent to the processing plant.

Harvesting FFB is not an easy job. It requires high strength due to the heavy work patterns. Thus, ergonomics are important factors to be studied. Even though there are many studies related to WMSD had been carried out before, such as Deros et al. [3] and Seaman [4]. However, there are very few studies that were related to work in palm oil plantations, especially during harvesting of FFB $[5,6]$. Therefore, in this study the authors shall focus on the prevalence of WMSD during harvesting FFB by using the RULA method.

\section{Methods}

\section{Study design}

A cross-sectional study was conducted in Kuala Selangor and data collection is done by doing faceto-face interviews, video recording and direct observation of FFB harvesters' working posture during harvesting FFB in oil palm plantation. 
Sample size

The sample size was 7 FFB harvesters, aged between 30 - 57 years old and FFB harvesters who had any history of accidents were excluded.

\section{Subjective Assessment}

The survey questionnaire was consisted of demographic information; age, educational level, smoking status and working experience in oil palm industry, while physical ergonomic factors consisted numbers of FFB harvested in a day and time required to harvest each FFB.

\section{RULA}

To further strengthen the data received from the Subjective Assessment conducted, the RULA method [7] was done on the subject during harvesting FFB. The observations were made on the occurrence of WMSD factors, i.e. work postures performed by the subjects. Figure 1 shows the RULA assessment method that has been carried out.

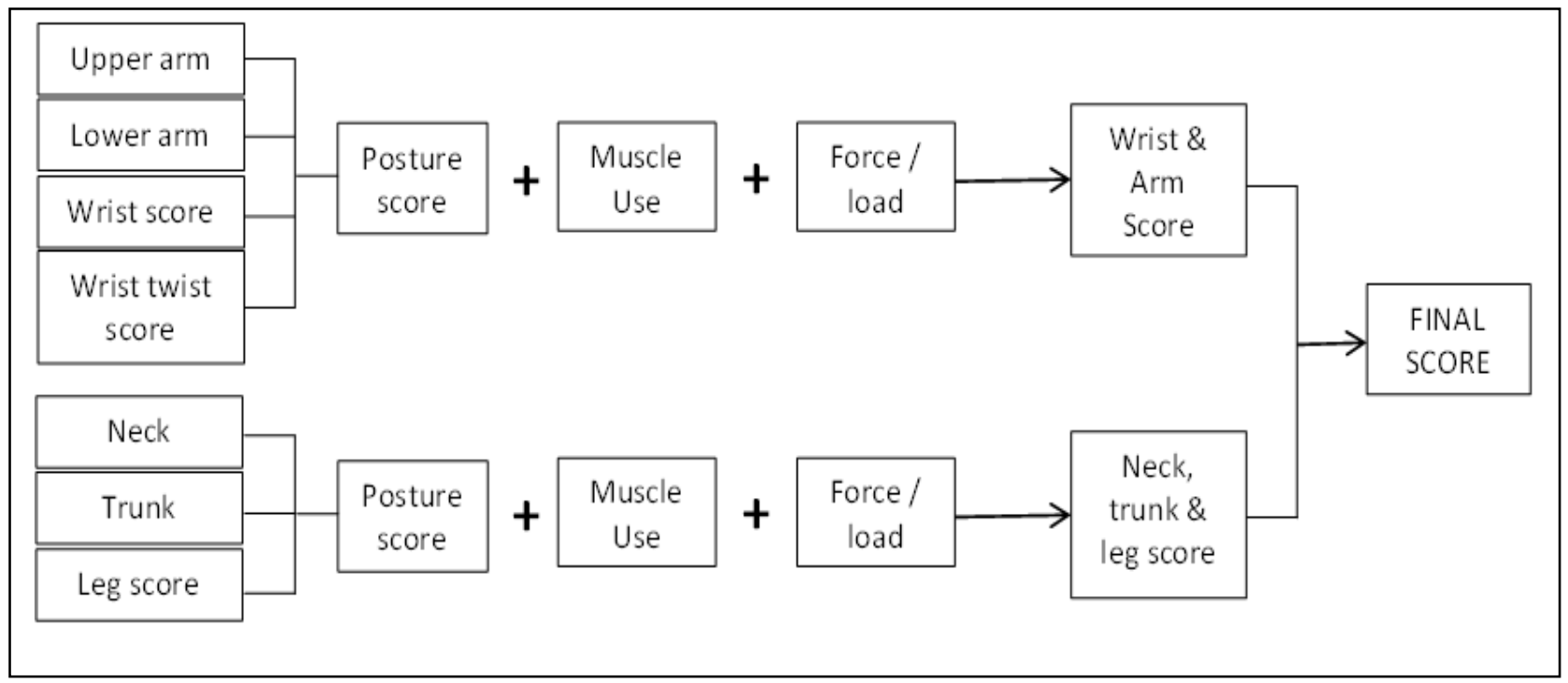

Figure 1 RULA assessment method

\section{Results}

\section{Demographic Data}

The number of subjects is 7 , and the mean age is 41.3 years and all of them are male. In addition, 5 of them are smokers and more than half have low education levels, i.e. up to lower secondary school. Details of the FFB harvester demographic data are shown in Table 1.

Table 1 Demographic Data of FFB Harvesters

\begin{tabular}{lc}
\hline Characteristics & N (\%) \\
\hline Age (mean \pm SD) yrs $=41.3 \pm 9.4$ & \\
Educational level & $3(42.8)$ \\
$\quad$ Primary school & $2(28.6)$ \\
Lower secondary school & $2(28.6)$ \\
Upper secondary school & \\
Smoking Status & $5(71.4)$ \\
Yes & $2(28.6)$ \\
No & 0 \\
Years smoking (mean \pm SD) yrs $=19.2 \pm 7.3$ & \\
Exercise frequency & \\
\hline
\end{tabular}


On average, subjects had been working in oil palm plantations for 12 years. Every day they will work for 6 hours with 1 hour break. They will harvest up to 88 bunches of FFB in each working day cycle. From the analysis, it was found that all of them had experienced work fatigue trough the activity. Table 2 shows the FFB harvesters' physical ergonomic factors in harvesting FFB in oil palm plantation.

Table 2 Physical Ergonomic Factors (N=7)

\begin{tabular}{lc}
\hline Characteristics & N (\%) \\
\hline Working experience (mean \pm SD) yrs $=12.1 \pm 9.3$ & \\
Working days in a month (mean \pm SD) days $=24.9 \pm 0.4$ & \\
Working hours in a day (mean \pm SD) hrs $=6.0 \pm 1.2$ & \\
Break duration (mean \pm SD) minute $=60.0 \pm 0.0$ & \\
Number of FFB harvested in a day (mean \pm SD) $88.6 \pm 3.8$ & \\
Time to harvest 1 FFB (mean \pm SD) sec $=4.1 \pm 1.5$ & \\
Experiencing work fatigue & $7(100)$ \\
Yes & 0 \\
No & $5(71.4)$ \\
Frequency having work fatigue & $2(28.6)$ \\
Sometimes & 0 \\
Frequently & \\
Always &
\end{tabular}

\section{Video recording observation}

Observation on video recording is made on the subject during the harvesting process. Only 6 subjects are recorded because 1 subject is driving a truck to collect all the harvested FFB. Figure 2 shows the selected harvesting work by the 6 subjects, which are taken from the original video recording.

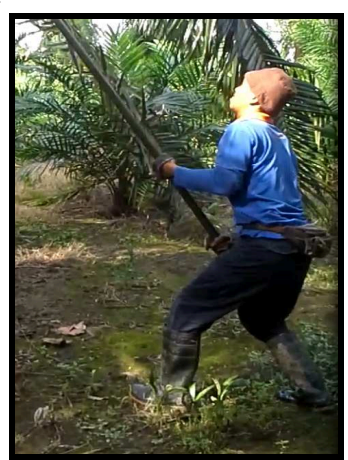

Subject 1

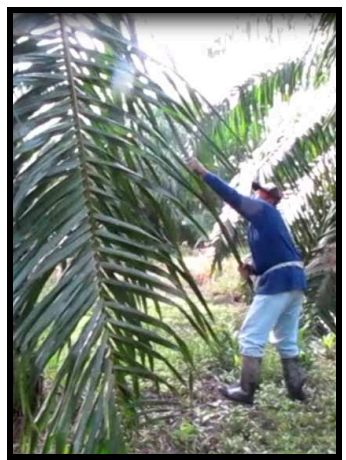

Subject 4

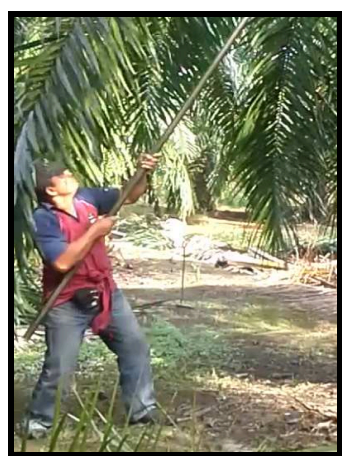

Subject 2

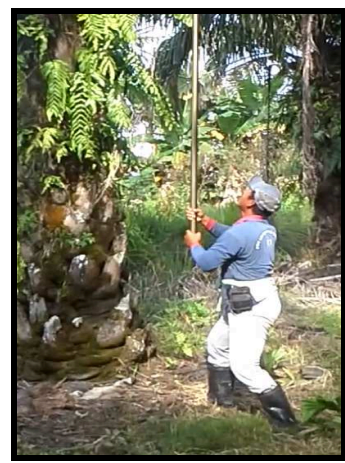

Subject 5

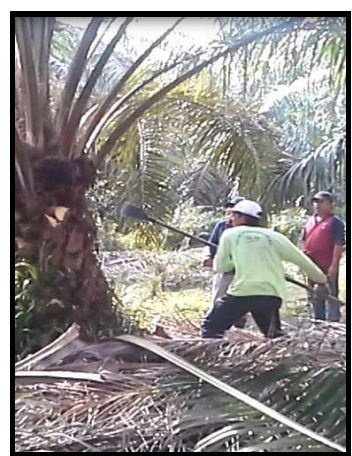

Subject 3

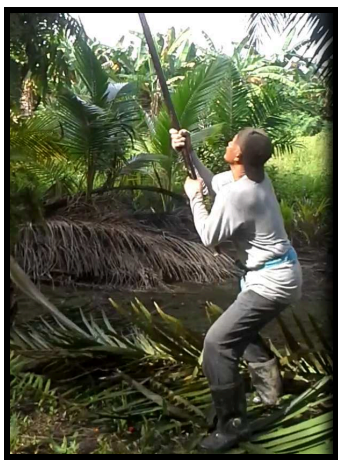

Subject 6

Figure 2 Selected harvesting work by the six subjects 


\section{Ergonomic risk using the RULA scoring method}

Table 3 shows the RULA scoring during harvesting FFB. All subjects have scored 5 for wrist and arm, while neck, trunk and leg score is ranging between 4 to 8 points. In addition, $83 \%$ of the final score is 7 , which indicates the harvesting posture need to be investigated and immediate change should be implemented. Table 2 also showed that only 1 person has scored 5, indicating that further investigation should be carried out and harvesting posture should be changed soon.

Table 3 RULA score during harvesting FFB

\begin{tabular}{cccc}
\hline Subject & $\begin{array}{c}\text { Wrist and arm } \\
\text { score }\end{array}$ & $\begin{array}{c}\text { Neck, trunk \& leg } \\
\text { score }\end{array}$ & Final score \\
\hline 1 & 5 & 7 & 7 \\
2 & 5 & 8 & 7 \\
3 & 5 & 4 & 5 \\
4 & 5 & 6 & 7 \\
5 & 5 & 6 & 7 \\
6 & 5 & 7 & 7 \\
\hline
\end{tabular}

\section{Discussion}

From the RULA score, it was found that high prevalence $(100 \%)$ of WMSD occurs during harvesting FFB, i.e. $83 \%$ of it needs to be changed immediately while $17 \%$ of it should be changed soon. This score is due to abnormal posture that the subjects had to carry out during harvesting FFB from tall trees. From previous studies, it shows that abnormal postures can give significant effect toward WMSD [8-11].

The length of the pole used by the subjects can also give effect towards WMSD. This is due to unmatched anthropometric data between the subject and the length of pole used. The anthropometric data are very important to help human limitation. Studies by Dhimmar et al. [12] shows that investing working tools according to anthropometric data can increase effectiveness and workers' performance.

Another factor that increases the WMSD during harvesting FFB is repetitive movement of the subject during the harvesting work. The subject has to pull the sickle many times before the FFB can be harvested. Studies from different kind of working sectors [13-19] shows that repetitive work will give a very high prevalence on WMSD to workers, and can lead to absentees due to the pain that they are facing.

From the RULA analysis that had been carried out, there is a constraint that is questionable. The force used by subjects during pulling the sickle while harvesting cannot be assessed. This due to EMG data is not recorded by the authors. Force is also one of factors that can lead to WMSD. From [20], it shows that EMG data will give an accurate value for the force use during harvesting. Therefore, the data collection can be improved by considering the EMG data, so that the prevalence of WMSD can be collected accurately.

\section{Conclusion}

This study shows that high prevalence occurs during harvesting oil palm fresh fruit bunches by using RULA method. The authors found that the prevalence occurrence are due to abnormal postures carried out during harvesting work, unmatched between the tool and anthropometric data, and the repetitive work carried by the workers. Therefore, further investigation and improvement is needed in this work area to prevent high risk of WMSD for this occupation. 


\section{References}

[1] Kushairi, A., A. Ismail, and E.A. Ghani, Industri Sawit di Malaysia, in Perusahaan Sawit di Malaysia - Satu Panduan, E.A. Ghani and I. Omar, Editors. 2009, Lembaga Minyak Sawit Malaysia (MPOB): Kuala Lumpur, Malaysia. p. 3-11.

[2] Deraman, M.S., Penjenteraan Di Ladang Sawit, in Perusahaan Sawit di Malaysia - Satu Panduan, E.A. Ghani and I. Omar, Editors. 2009, Lembaga Minyak Sawit Malaysia (MPOB): Kuala Lumpur, Malaysia. p. 282-305.

[3] Deros, B.M., et al., An Ergonomics Study on Assembly Line Workstation Design. American Journal of Applied Sciences, 2011. 8(11): p. 1195-1201.

[4] Seaman, F.A., Assessment of Shoulder Loads and Postures Experienced by Automotive Seat Frame Assembly Workers in Relation to Shoulder Pain 2007: University of New Brunswick (Canada).

[5] Owolarafe, O. and C. Arumughan, A Review of Oil Palm Fruit Plantation and Production Under the Contract-Growers Scheme in Andhra Pradesh and Tamil Nadu States of India. 2007.

[6] Zainuddin, M.F. and R.A. Haslam, Musculoskeletal Disorders Arising From the Harvesting of Palm Oil Fruit in Malaysia. Contemporary Ergonomics, 1996: p. 221-226.

[7] McAtamney, L. and E.N. Corlett, RULA: A Survey Method for the Investigation of WorkRelated Upper Limb Disorders. Applied Ergonomics, 1993. 24(2): p. 91-99.

[8] Earle-Richardson, G., et al., An Ergonomic Intervention to Reduce Back Strain Among Apple Harvest Workers in New York State. Applied Ergonomics, 2005. 36(3): p. 327-334.

[9] Plamondon, A., et al., Manual Materials Handling in Mining: The effect of Rod Heights and Foot Positions when Lifting "in-the-hole" Drill Rods. Applied Ergonomics, 2006. 37(6): p. 709-718.

[10] Sangeun, J., R. McCulloch, and G.A. Mirka, Biomechanical Evaluation of Postures Assumed when Harvesting from Bush Crops. International Journal of Industrial Ergonomics, 2009. 39(2): p. 347-352.

[11] Shanahan, E.M. and R. Sladek, Shoulder Pain at the Workplace. Best Practice \& Research Clinical Rheumatology, 2011. 25(1): p. 59-68.

[12] Dhimmar, V., S. Sheth, and S. Shah, Proposed Design of Workstation for Rural Blacksmith. 2011.

[13] Beach, J., A. Senthilselvan, and N. Cherry, Factors Affecting Work-Related Shoulder Pain. Occupational Medicine, 2012. 62(6): p. 451-454.

[14] Melzer, A.C.S. and A.M. Iguti, Working Conditions and Musculoskeletal Pain Among Brazilian Pottery Workers. Cadernos de Saúde Pública, 2010. 26(3): p. 492-502.

[15] Leclerc, A., et al., Incidence of Shoulder Pain in Repetitive Work. Occupational and Environmental Medicine, 2004. 61(1): p. 39-44.

[16] Andersen, J.H., et al., Physical, Psychosocial, and Individual Risk Factors for Neck/Shoulder Pain with Pressure Tenderness in the Muscles Among Workers Performing Monotonous, Repetitive Work. Spine, 2002. 27(6): p. 660-667.

[17] Descatha, A., et al., Description of Outcomes of Upper-Extremity Musculoskeletal Disorders in Workers Highly Exposed to Repetitive Work. The Journal of Hand Surgery, 2009. 34(5): p. 890-895. 
[18] Coury, H.J.C.G., J.A. Léo, and S. Kumar, Effects of Progressive Levels of Industrial Automation on Force and Repetitive Movements of the Wrist. International Journal of Industrial Ergonomics, 2000. 25(6): p. 587-595.

[19] Machado, G.A.D.L. and A.J.B. Villaverde, Design of an Electronic Instrumentation for Measuring Repetitive Hand Movements During Computer Use to Help Prevent Work Related Upper Extremity Disorder. International Journal of Industrial Ergonomics, 2011. 41(1): p. 1-9.

[20] Nimbarte, A.D., Risk of Neck Musculoskeletal Disorders Among Males and Females in Lifting Exertions. International Journal of Industrial Ergonomics, 2013: p. 1-7. 